\title{
Tools for Assessing the Creative Person, Process, and Product in Engineering Education
}

\section{Ms. Kristin Lerdal, South Dakota School of Mines and Technology}

Kristin Lerdal is an Undergraduate Research Assistant studying creativity in engineering education at the South Dakota School of Mines and Technology. She is working towards a Bachelors of Science degree in Civil Engineering with an Environmental Emphasis.

\section{Dr. Andrea E. Surovek, South Dakota School of Mines and Technology}

Dr. Andrea Surovek is a research scientist working in the areas of biomimicry for sustainable construction and engineering education at the South Dakota School of Mines and Technology. She is the recipient of the ASEE CE Division Seeley Fellowship and the Mechanics Division Beer and Johnston Outstanding New Mechanics Educator Award. She is a fellow of ASCE and ASCE/SEI. She received her PhD from Georgia Tech, and also holds degrees in both Civil Engineering and Visual and Performing Arts from Purdue University

\section{Dr. Kristen S. Cetin, Iowa State University}

Dr. Kristen S Cetin is an Assistant Professor at Iowa State University in the Department of Civil, Construction and Environmental Engineering.

\section{Dr. Bora Cetin, Iowa State University}

Assistant Professor in the Department of Civil, Construction, and Environmental Engineering

\section{Dr. Benjamin Ahn, Iowa State University}




\section{WIP: Assessing the Creative Person, Process, and Product in Engineering Education.}

\section{Introduction: why assess creativity?}

This work-in-progress paper investigates different instruments for assessing individual creativity, an essential tool to engineers. Historically, the basis for most modern engineering curricula can be traced to the 1955 ASEE recommendations on engineering curricular, aka the Grinter report [1] that recommends "an integrated study of engineering analysis, design, and engineering systems for professional background, planned and carried out to stimulate creative and imaginative thinking [...]". The National Academies of Engineering have identified grand challenges for engineering [2] that recognize that society is growing at an exponential rate in terms of population and technology. These new problems are complex, transdisciplinary and cannot be solved with old solutions; they require creative solutions. Engineering societies have also recognized this need. In the last decade, a number of vision statements on the future of engineering education [e.g. 3,4] point to the fact that creativity is essential to engineering innovation; it is regarded as an important attribute in the education of engineers in order to meet these urgent national and global challenges and to drive economic growth in the new millennium.

There are many barriers to encouraging and enhancing student creativity in engineering classrooms including deductive approaches that produce a single "right answer" and the consideration of engineering as serious and accurate rather than creative. Kazerounian and Foley [5] present a strong case for how the environment negatively impacts creativity in engineering students. They suggest that the elements inherent to creativity - use of non-standard approaches, risk, and learning through failures, are not amenable and are actively discouraged in engineering education.

One additional barrier to including creativity as an outcome in engineering course is determining how faculty can assess the effectiveness of these efforts. This study aims to aid faculty and researchers interested in adding creativity as an objective in the classroom by identifying metrics for measuring creativity with respect primarily to person and product. A variety of instruments that assess the creative person, process, and product are investigated to determine their primary attributes with respect to ease of use and expertise required to score.

\section{The four "p"s of creativity}

Using assessment methods requires a basic understanding of the nomenclature commonly used by creativity researcher. Measures of creativity have traditionally split into four branches, initially labeled the Four Ps by Rhodes [6] person (individual attitudes and habits), process (problem-solving steps and nuances), product (the tangible results of process), and press (the surrounding environment). Selecting an instrument to measure creative outcomes is aided by understanding which attribute of creativity is being measured [7]. In general, studies on assessing engineering creativity focus on creative person or the creative product [8]. Creative process is a more complicated procedure; while simple divergent thinking tests might be thought of as 
assessing process, full process assessment is more complicated and requires evaluation of problem definition and selection which can have a strong effect on quality of solution [9].

Because much of engineering is focused on design, product is often paramount; it is the unifying factor between engineering and creativity [8]. Because of this, educators may be most interested in assessing the level of creativity displayed in final products; however, it may well be worth educators' time to also assess the creative person and their creative process that results in such creative products so that the traits exhibited by the person may be fostered and developed to produce even stronger creative products. Cropley proposes an evolution of solutions as follows:

1. A solution is effective.

2. A creative solution is novel and effective

3. An elegant solution has elevated novelty, effectiveness, and aesthetics.

4. A solution exhibiting genesis has elevated elegance, novelty, and aesthetics and causes a paradigm shift within the domain.

\section{Is creativity domain specific?}

Two schools of thought exist when further classifying the creative skill-set: one school believes that creativity is founded in knowledge and experience and gained over time without regard to a specific domain [10] while the second believes creativity is domain specific and may be unrelated across domains $[11,12]$. That creativity requires expertise in a field lends itself to domain being relevant in the creative process; for example, a poet of renown is not necessarily going to produce an innovative engineering design nor is an engineer going to write an awardwinning poem. It is not impossible, but it is not predicted by any known assessments.

An alternative to defining creativity as domain-general or domain-specific is to recognize creativity as a habit that can be developed and applied to a variety of situations or domains [13] while creative products and creative achievement are domain specific. The level of knowledge and experience needed to master a domain and exhibit creative achievement may not leave time for a single person to be successful in more than one domain [14]. Similarly, a creative product must be both novel and applicable to the problem it solves, meaning that domain-specific knowledge is required to solve the problem, and the solution is unlikely to work in other domains [15].

\section{Instruments to assess creativity}

The easiest assessments to administer are those that assess the creative person, which has several instruments designed around its assessment. These instruments all rely on accurate self-reporting from the participants but offer decent predictability of future creative behavior and achievement [16]. These instruments also take little time to complete and are low-costs, as the instruments and their supporting literature can be accessed online at no cost. Each of these instruments, while not directly measuring creativity with regard to science and engineering, have questions that pertain to the field. The instruments identified in this study as measuring creative person include:

- $\quad$ The Kaufman Domains of Creativity Scale (KDOCS) [17] 
- The Creative Behavior Inventory (CBI) [18]

- The Creative Domains Questionnaire (CDQ) [19]

- Revised Creative Domains Questionnaire (CDQ-R) [20]

- The Creative Achievement Questionnaire (CAQ) [21]

One caveat to testing creative person is that there are innumerous online or computer-based tests to self-assess creativity. Most are not validated instruments; many are easy to manipulate to obtain desired results, and few provide any domain specificity.

Assessments of creative process and product are not self-assessments or simple questionnaires. these assessments require more time to both complete and score, and they also require expertise to accurately score. As such, the resulting scores give greater insight into the true creative skills of the participants. Two such instruments have set the standards in the field of creativity studies: The Torrance Tests of Creative Thinking (TTCT) [22,23] and the Consensual Assessment Technique (CAT) [24]. A variation of the CAT is the Creative Solution Diagnostic Scale create specifically for engineering design [25]. Table 1 outlines a list of validated creativity assessments and identifies them as measures of creative person, process or product.

\section{Attributes of assessment tools}

The intent of this project is not to judge assessment metrics, recognizing that different applications require different attributes and outcomes of assessment metrics. Instead, the intent is to provide guidelines for engineering educators and researchers interested in creativity for selecting appropriate metrics to be used in classrooms and research studies based on metric attributes. but rather to compile a These metrics are examined for applicability to science and engineering, ease of administration and completion, expertise required to score, cost to administer, and time required to administer.

Along with being low-cost and low-time commitment, the instruments of creative person are easiest to administer and require the least expertise to score. They offer acceptable predictive ability of future creativity [16] while the TTCT offers the most validated predictive ability [23] and the CAT offering no predictive ability [24]. The TTCT and the CEDA also require training to score, while the CAT requires acknowledged expertise in the domain in question.

Table 2 provides a ranking system of all the instruments' characteristics based on the traits that are often influential when selecting an instrument. Rankings were assessed according to seminal and or validating literature regarding each instrument. Many of the instruments are comparable in several aspects; the instruments that assess creative person are equal in terms of cost and relative predictability of future creativity [16]. Numbers with an asterisk denote a tie in rank.

\section{Conclusion}

For creativity to become part of measurable outcomes in engineering education, faculty and researchers must have the ability to assess the effectiveness of their approaches. This paper presents the early stages of work to delineate qualities of creativity assessments for the benefit of such efforts. 
Table 1: Assessments of creativity and primary attributes

\begin{tabular}{|c|c|c|}
\hline Instrument & Description & $\begin{array}{l}\text { Assessment } \\
\text { Type }\end{array}$ \\
\hline $\begin{array}{l}\text { The Kaufman Domains of } \\
\text { Creativity Scale (KDOCS) }\end{array}$ & $\begin{array}{l}\text { A } 50 \text {-question assessment that yields a score that ranks a person's self- } \\
\text { perceived creative abilities as compared to their peers. Questions fall into } \\
\text { the domains of everyday, scholarly, performance, Math/science, and } \\
\text { artistic. These scores can be used to assess the participant's overall } \\
\text { creativity across all domains. } 50 \text { questions. Likert scale. }\end{array}$ & Person \\
\hline $\begin{array}{l}\text { The Creative Behavior } \\
\text { Inventory }\end{array}$ & $\begin{array}{l}\text { Assesses frequency of engagement in activities often done by highly } \\
\text { creative people, broken into six domains: fine arts, crafts, literature, music, } \\
\text { performing arts, and math/science. Answers score } 0-3 \text { pointsA composite } \\
\text { score measures the participant's overall frequency of creative behavior, } \\
\text { and individual scores to questions can be used to assess the participant's } \\
\text { creative behavior in a specific domain. } 90 \text { questions. }\end{array}$ & Person \\
\hline $\begin{array}{l}\text { The Creative Domains } \\
\text { Questionnaire (CDQ) }\end{array}$ & $\begin{array}{l}\text { Determines a person's strongest creative domains. Each question relates to } \\
\text { a specific domain, with the CDQ covering } 56 \text { domains and the CDQ-R } \\
\text { covering } 21 \text {. Responses to the question are on a six-point scale. The } \\
\text { composite score assesses the participant's general creativity across all } \\
\text { domains, while each singular response measures their creativity within the } \\
\text { given domain }\end{array}$ & Person \\
\hline $\begin{array}{l}\text { Revised Creative Domains } \\
\text { Questionnaire (CDQ-R) }\end{array}$ & Shortens the CDQ from 56 domains to 21. & Person \\
\hline $\begin{array}{l}\text { The Creative Achievement } \\
\text { Questionnaire (CAQ) }\end{array}$ & $\begin{array}{l}\text { Assesses a person's field of greatest creative achievement. It contains } 12 \\
\text { questions that span ten domains, as well as a question asking for the } \\
\text { participant's self-perceived strengths and a question asking for creative } \\
\text { achievements not covered by the other questions. The domains covered in } \\
\text { the CAQ are visual arts, music, dance, architectural design, creative } \\
\text { writing, humor, inventions, scientific discovery, theater and film, and } \\
\text { culinary arts. The responses are numbered from } 0 \text { to } 7 \text {, Responses to the } \\
\text { final question about other creative achievements not covered by the ten } \\
\text { domains are not scored but are important insights into the participant's } \\
\text { creative strengths }\end{array}$ & Person \\
\hline $\begin{array}{l}\text { The Torrance Tests of } \\
\text { Creative Thinking (TTCT) }\end{array}$ & $\begin{array}{l}\text { Two main froms - written and visual. A test of divergent thinking. These } \\
\text { scores can be used to predict creativite ability more than a decade after } \\
\text { completion. Equires expert scoring. }\end{array}$ & $\begin{array}{l}\text { Person / } \\
\text { product }\end{array}$ \\
\hline $\begin{array}{l}\text { Consensual Assessment } \\
\text { Technique (CAT) }\end{array}$ & $\begin{array}{l}\text { Experts in a domain assess the creative products of a sample of participants } \\
\text { and rank each product in order of creativity as compared to the other } \\
\text { products of the sample. The basis of the CAT is the assumption that experts } \\
\text { in a field are the most capable of recognizing creative talent. For this } \\
\text { reason, the CAT is known as the "Gold Standard" of creativity assessments } \\
\text { Requires expert scoring and does not predict future creative ability }\end{array}$ & Product \\
\hline $\begin{array}{l}\text { Creative Solution } \\
\text { Diagnosis Scale (CSDS) }\end{array}$ & $\begin{array}{l}\text { A CAT-type assessment specific to engineering / design products. 30-item } \\
\text { scale based on a core of four criteria: Relevance \& Effectiveness, Novelty, } \\
\text { Elegance, and Genesis. Shown to have high reliability even with non- } \\
\text { expert scoring. }\end{array}$ & Product \\
\hline $\begin{array}{l}\text { Creative Engineering } \\
\text { Design Assessment } \\
\text { (CEDA) }\end{array}$ & $\begin{array}{l}\text { Assesses the creative process. Since the engineering process differs greatly } \\
\text { from most critical thinking processes in its requirement of both divergent } \\
\text { and convergent thinking, this instrument is best for capturing an } \\
\text { individual's creative abilities in the creative process. }\end{array}$ & Process \\
\hline
\end{tabular}


Table 2: Characteristic Ranking of Creativity Instruments

\begin{tabular}{|c|c|c|c|c|c|c|c|c|c|}
\hline \multicolumn{2}{|c|}{ Least Expensive } & \multicolumn{2}{|c|}{ Most Predictive } & \multicolumn{2}{|c|}{$\begin{array}{l}\text { Shortest } \\
\text { Duration }\end{array}$} & \multicolumn{2}{|c|}{$\begin{array}{c}\text { Easiest to } \\
\text { Administer }\end{array}$} & \multicolumn{2}{|c|}{$\begin{array}{c}\text { Least Expertise } \\
\text { to Score }\end{array}$} \\
\hline $1 *$ & CDQ-R & 1 & TTCT & 1 & $\mathrm{CAQ}$ & $1 *$ & CDQ-R & $1 *$ & CDQ-R \\
\hline $1 *$ & CDQ & $2 *$ & CBI & 2 & CDQ-R & $1 *$ & CDQ & $1 *$ & CDQ \\
\hline $1 *$ & KDOCS & $2 *$ & CAQ & 3 & KDOCS & $1 *$ & KDOCS & $1 *$ & KDOCS \\
\hline $1 *$ & CAQ & $2 *$ & KDOCS & 4 & CDQ & $1 *$ & CAQ & $1 *$ & CAQ \\
\hline $1 *$ & CBI & $2^{*}$ & CDQ & 5 & $\mathrm{CBI}$ & $1 *$ & CBI & $1 *$ & $\mathrm{CBI}$ \\
\hline 6 & CEDA & $2 *$ & CDQ-R & 6 & CEDA & 6 & CEDA & 6 & CEDA \\
\hline 7 & TTCT & 7 & CEDA & 7 & CAT & 7 & TTCT & 7 & TTCT \\
\hline 8 & CAT & 8 & CAT & 8 & TTCT & 8 & CAT & 8 & CAT \\
\hline \multicolumn{2}{|c|}{ Most Expensive } & \multicolumn{2}{|c|}{ Least Predictive } & \multicolumn{2}{|c|}{$\begin{array}{l}\text { Longest } \\
\text { Duration }\end{array}$} & \multicolumn{2}{|c|}{$\begin{array}{l}\text { Most Difficult to } \\
\text { Administer }\end{array}$} & \multicolumn{2}{|c|}{$\begin{array}{c}\text { Most Expertise } \\
\text { to Score }\end{array}$} \\
\hline
\end{tabular}

\section{Acknowledgements}

This work was funded in part by National Science Foundation Grant DUE \#1712195. The project is entitled "Collaborative Research: Bridging the gap between academia and industry in approaches for solving ill-structured problems". Data, findings, and conclusions or recommendations are those of the authors, only.

\section{References}

[1] American Society of Engineering Education (ASEE). "Report of the ASEE Committee on Evaluation of Engineering Education," Journal of Engineering Education, Sept. 25, 1955, pp. 25-60. Reprinted in Journal of Engineering Education, vol. 83, no. 1, 1994, pp. 74-94.

[2] NAE Grand Challenges for Engineering, http://www.engineeringchallenges.org last accessed $4 / 29 / 19$

[3] ASCE Structural Engineering Institute. A Vision for the Future of Structural Engineering and Structural Engineers: A case for change, Board of Governors, ASCE, Reston VA. 2013. Accessed online on 3/22/2019 at http://www.asce.org/uploadedFiles/visionforthefuture.pdf

[4] National Academies of Engineering. The Engineer of 2020 Visions of Engineering in the New Century. The National Academies Press, Washington, D.C. 2004.

[5] Kazerounian, K., \& Foley, S. Barriers to creativity in engineering education: A study of instructors and students' perceptions. Journal of Mechanical Design, 129(7), 761-768, 2007.

[6] Rhodes, M. An Analysis of Creativity. Phi Delta Kappan, 42(7), 305-310, 1961.

[7] Belski, I. Engineering Creativity- How to Measure It? Paper presented at the $28^{\text {th }}$ Annual Conference of the Australasian Association for Engineering Education, Manly, Sydney, Australia, 2017.

[8] Cropley, D. H. Creativity in Engineering: Novel Solutions to Complex Problems:

Elsevier, 2015. 
[9] Arreola, N. J., \& Reiter-Palmon, R. The effect of problem construction creativity on solution creativity across multiple everyday problems. Psychology of Aesthetics, Creativity, and the Arts, 10(3), 287-295, 2016.

[10] Plucker, J. A. Beware of Simple Conclusions: The Case for Content Generality of Creativity. Creative Research Journal, 11(2), 179-182, 1998.

doi:10.1207/s15326934crj1102_8

[11] Baer, J. The Case for Domain Specificity of Creativity. Creativity Research Journal, 11(2), 173-177, 1998.

[12] Kaufman, J. C., \& Baer, J. Sure, I'm creative-but not in mathematics!: Self-reported creativity in diverse domains. Empirical Studies of the Arts, 22,143-155, 2004.

[13] Sternberg, R. J. The Assessment of Creativity: An Investment-Based Approach. Creativity Research Journal, 24(1), 3-12, 2012. doi:10.1080/10400419.2012.652925

[14] Kaufman, J. C., \& Baer, J. Could Steven Spielberg Manage the Yankees?: Creative Thinking in Different Domains. Korean Journal of Thinking and Problem Solving, 12(2), 5-14, 2002.

[15] Baer, J., \& Kaufman, J. C. Bridging Generality and Specificity: The Amusement Park Theory (APT) Model of Creativity. Roeper Review, 27(3), 158-163, 2005.

[16] Sheldon, K. M. Creativity and self-determination in personality. Creativity Research Journal, 8, 61-72, 1995.

[17] Kaufman, J. C. Counting the Muses: Development of the Kaufman Domains of Creativity Scale (K-DOCS). Psychology of Aesthetics, Creativity, and the Arts, 6(4), 298-308, 2012. doi:10.1037/a0029751

[18] Hocevar, D. The Development of the Creative Behavior Inventory (CBI). Paper presented at the Annual Meeting of the Rocky Mountain Psychological Association, 1979.

[19] Kaufman, J. C., Cole, J. C., \& Baer, J. The construct of creativity: Structural model for selfreported creativity ratings. Journal of Creative Behavior, 43, 119-134, 2009.

[20] Kaufman, J. C., \& Beghetto, R. A. Beyond Big and Little: The Four C Model of Creativity. Review of General Psychology, 13(1), 1-12, 2009. doi:10.1037/a0013688

[21] Carson, S., Peterson, J. B., \& Higgins, D. M. Reliability, Validity, and Factor Structure of the Creative Achievement Questionnaire. Creativity Research Journal, 17(1), 37-50, 2005. doi:10.1207/s15326934crj1701_4

[22] Torrance, E. P. Predictive Validity of the Torrance Tests of Creative Thinking. Journal of Creative Behavior, 6(4), 236-252, 1972.

[23] Torrance, E. P. Torrance Tests of Creative Thinking. Lexington, Massachusetts: Xerox Corporation, 1974.

[24] Amabile, T. M. Social Psychology of Creativity: A Consensual Assessment Technique. Journal of Personality and Social Psychology, 43(5), 997-1013, 1982.

[25] Cropley, D., \& Kaufman, J. C. Measuring functional creativity: Non-expert raters and the creative solution diagnosis scale. The Journal of Creative Behavior, 46, 119-137, 2012. http://dx.doi.org/10.1002/jocb.9 